\title{
De siervos y cautivos. La génesis de la esclavitud moderna desde la legislación española medieval y la práctica indiana
}

Resumen: Desde el inicio, la colonización española contó con esclavos negros en las expediciones y contingentes enviados a América. La continuidad temporal entre la "reconquista" de Granada y la "conquista" de América permitió la transposición de algunas prácticas que marcaron profundamente las experiencias sociales del mundo atlántico. En artículo pretende delinear las influencias que el derecho medieval ejerció sobre la esclavitud moderna en América. Se enfoca principalmente en los conceptos y en las normativas sobre cautivos y siervos, sin perder de vista que no todo derecho está contenido en los códigos legales.

Palabras clave: cautivos, siervos, derecho de Indias, tráfico de esclavos, rescates.

\section{On servants and captives. The genesis of modern slavery: medieval Spanish legislation and Indian practice}

Abstract: At first, the Spanish colonization counted on black slaves in the expeditions and contingents sent to America. The temporal continuity between the "reconquest" of Granada and the "conquest" of America allowed the transposition of some practices that deeply marked the social experiences of the Atlantic World. This article explores the influences that medieval law exerted on modern slavery in America. The analysis mainly focuses on the captive and servant concepts and regulations, considering that not all right is contained in the legal codes.

Keywords: captives, servants, West Indies' Law, slave trade, ransoms.

\section{De servos e cativos. A gênese da escravidão moderna a partir da legislação espanhola medieval e da prática nas Índias}

Resumo: Desde o início, a colonização espanhola teve escravos negros em expedições e nos contingentes enviados para a América. A continuidade temporal entre a "reconquista" de Granada e a "conquista" da América permitiu a transposição de algumas práticas que marcaram profundamente as experiências sociais do mundo atlântico. Neste artigo procuramos analisar as influências que o direito medieval exerceu sobre a escravidão moderna na América. Enfoca-se principalmente os conceitos e regulamentos sobre cativos e servos, sem perder de vista que nem todo direito está contido nos códigos legais.

Palavras-chave: cativos, servos, direito das Índias, tráfico de escravos, resgates.

Cómo citar este artículo: María Verónica Secreto, "De siervos y cautivos. La génesis de la esclavitud moderna desde la legislación española medieval y la práctica indiana”, Trashumante. Revista Americana de Historia Socia/19 [2022]: 6-27.

DOl: 10.17533/udea.trahs.n19a01

Fecha de recepción: 26 de febrero de 2021

Fecha de aprobación: २० de agosto de २०२१

María Verónica Secreto: Doctora en Historia Económica por la Universidad Estadual de Campinas. ProfesoA ra titular de la Universidad Federal Fluminense e investigadora del Conselho Nacional de Desenvolvimento Científico e Tecnológico y de la Fundação de Amparo à Pesquisa do Estado do Rio de Janeiro, y de los grupos de investigación Escrita da História. Historiografias do Sul y Afrolatinoamerica: estudos comparados, ambos de la Universidad Federal Fluminense. ORCID: 0000-0002-3403-4810.

Correo electrónico: mvsecreto@yahoo.com 


\title{
De siervos y cautivos. La génesis de la esclavitud moderna desde la legislación española medieval y la práctica indiana*
}

\author{
María Verónica Secreto
}

"En la Ciudad de Argel, que es tierra de moros en la Berbería a diez días del mes de octubre año de mil quinientos ochenta años, ante el Ilustre y Muy Reverendo Señor Fray Joan Gil Redemptor de Spaña, de la Corona de Castilla por Su Majestad, paresció presente, Miguel de Cervantes, esclavo que ha sido, que ahora está franco y rescatado". "Información hecha en Argel a solicitud de Miguel de Cervantes Saavedra, acerca de los servicios y padecimientos prestados y sufridos por el mismo", 10 de octubre de 1580. http://www.cervantesvirtual.com/ nd/ark:/59851/bmcnp204.

\section{Introducción}

En las instrucciones al comendador fray Nicolás de Ovando, emitidas en el año - 1501, aparece la primera mención a la esclavitud negra en relación con las Américas: "Non consentireis nin dareis logar que alla vayan moros nin xudios, nin erexes, nin reconcyliados, nin personas nuevamente convertidas a nuestra fe, salvo si fueren esclavos negros $u$ otros esclavos que fayan nascido en poder de cristhianos, nuestros subditos e naturales". ${ }^{1}$ Los primeros mencionados, a quienes se les prohíbe ser llevados a las islas y Tierra Firme del Mar Océano, son los judíos,

* Esta investigación cuenta con el apoyo de la Fundação de Amparo à Pesquisa do Estado do Rio de Janeiro (FAPERJ), Cientista de Nosso Estado y del Conselho Nacional de Desenvolvimento Científico e Tecnológico (CNPq), Productividade em Pesquisa. Parte de la investigación fue desarrollada durante la estadía como fellow en la Universidad de Harvard entre el otoño de 2019 y el verano de 2020.

1. Antonio Rumeu de Armas, La política indigenista de Isabel la Católica (Valladolid: Instituto "Isabel la Católica” de Historia Eclesiástica, 1969) 373-376. Según Gonzalo Aguirre Beltrán, la primera medida para regular la migración de esclavos fue esta instrucción. Gonzalo Aguirre Beltrán, La población negra de México. Estudio etnohistórico (México: Fondo de Cultura Económica, 1972) 16-17; José Luis Cortés López, Carlos I y el comercio de esclavos (Alicante: Biblioteca Virtual Miguel de Cervantes, 2001). 
herejes, reconciliados y cristianos nuevos, aquellos que podrían poner en peligro la evangelización de los indios. Aunque este peligro parecía desvanecerse en el caso de que los recién convertidos fueran esclavos negros u otros esclavos nacidos entre cristianos.

No sin contradicciones, en las primeras décadas del siglo XVI se osciló entre permisos y prohibiciones para la introducción de esclavos negros, con ambigüedades semejantes sobre la esclavitud de los indios. ${ }^{2}$ Durante todo el siglo XVI, instrucciones, licencias y capitulaciones sirvieron como marcos legales para la importación de esclavizados. ${ }^{3}$ A partir de 1595, el contrato otorgado a Pedro Gomes Reynel abrió el camino para una nueva forma de realizar el abastecimiento de esclavos: el asiento. ${ }^{4}$

En un análisis realizado sobre el universo de las 70 capitulaciones negociadas en el siglo XVI, se observó que 31 de ellas incluyeron la concesión o permiso para la introducción de esclavos. ${ }^{5}$ Por ejemplo, en la Capitulación de Toledo, la reina Isabel le concedió permisos y beneficios a Francisco de Pizarro para la conquista del Perú, entre ellos: "Otro sí, que vos daremos licencia, como por la presente vos la damos, para que destos Nuestros Reynos, ó del Reyno de Portugal, ó Yslas de CaboVerde, ó de donde vos ó quien vuestro poder oviere, quisiér[e]des e por bien tubier[e]des, podais pasar y pase á la dicha tierra de vuestra governacion, cinquenta esclavos negros". ${ }^{6}$

La temprana llegada de esclavizados negros a América y la trata son cosas diferentes. La historiografia se ha encargado de enunciar esos dos fenómenos sin profundizar en las marcas de la diferenciación. ${ }^{7}$ No obstante, las continuidades son importantes para explicar la forma que adoptó la esclavitud negra en las Indias de manera que: "No hubo necesidad de justificar la esclavitud africana en América, pues llegó ya sobradamente 'justificada'. No fue preciso estudiar sus causas, ni el derecho que asistía a los españoles para sostener tal institución, como en el caso de la esclavitud indígena, pues todo esto se había hecho en la antigüedad y el medievo". 8

2. Nancy E. van Deusen, Global Indios: The Indigenous Struggle for Justice in Sixteenth-Century Spain (Durham / Londres: Duke University Press, 2015).

3. Cortés López 1.

4. Carlos Sempat Assadourian, El tráfico de esclavos en Córdoba de Angola a Potosí. Siglos XVI-XVII (Córdoba: Dirección General de Publicaciones, 1966); Carlos Sempat Assadourian, El tráfico de esclavos en Córdoba, 1588-1610, según las actas de protocolos del Archivo Histórico de Córdoba (Córdoba: Dirección General de Publicaciones, 1965); Enriqueta Vila Vilar, "Los asientos portugueses y el contrabando de negros", Anuario de Estudios Americanos 30 (1973): 558.

5. Cortés López 17-18.

6. Ricardo Aranda, Colección de los tratados, convenciones, capitulaciones, armisticios y otros actos diplomáticos y políticos celebrados desde la Independencia hasta el día, t. 1 (Lima: Imprenta del Estado, 1890) 30.

7. Henry Kamen, "El negro en Hispanoamérica 1500-1700", Anuario de Estudios Americanos 28 (1971): 121-137.

8. Manuel Lucena Salmoral, "Leyes para esclavos. El ordenamiento jurídico sobre la condición, tratamiento, defensa y represión de los esclavos en las colonias de la América española", Tres grandes 
Sin embargo, esta ausencia de justificación no se mantuvo con el tiempo y durante el siglo XVI e inicios del XVII, muchos autores escribieron sobre el tema. Personajes como Tomás de Mercado, Bartolomé Frías de Albornoz, Luis de Molina, Tomás Sánchez, Francisco García, Fernando Rebello, Bautista Fragoso, Esteban Fagúndez y Pedro de Ledesma atendieron a la necesidad de actualizar los argumentos de la esclavitud. ${ }^{9}$ Así, construyeron los puentes legales y argumentativos entre la esclavitud tardomedieval y la moderna, entre unos grupos étnicos y otros, y entre unos territorios y otros "nuevos". Toda la discusión sobre la esclavitud negra es tardía, dice Antonio Manuel Hespanha, sobre todo si la comparamos con la reacción doctrinal a la conquista y esclavización de los indios americanos, casi inmediata. "Há razões para isso. Em primeiro lugar, a escravização de africanos não era desconhecida na Europa, onde já antes chegavam escravos negros. Nesse sentido era algo de estabelecido no direito de Europa". ${ }^{10}$

\section{La esclavitud y el derecho indiano}

Beatriz Bernal Gómez afirma que el derecho indiano nació unos meses antes de que Cristóbal Colón dejara el puerto de Palos, cuando le fueron otorgadas las Capitulaciones de Santa Fe en abril de $1492 .{ }^{11}$ Si bien su nacimiento puede ser datado, el contenido de ese derecho no puede ser restringido a las leyes que fueron creadas para las Indias. Por eso, entender el derecho indiano como aquel compuesto por pragmáticas, ordenanzas, reales cédulas, instrucciones, capitulaciones, decretos y reglamentos promulgados por los monarcas españoles y otras autoridades para tener vigencia en las Indias, supone entenderlo de forma restrictiva.

Por derecho indiano se entiende el sistema jurídico que fue aplicado en América y Filipinas, e incluye las disposiciones sancionadas con una clara intención territorial, ${ }^{12}$ las normas del derecho castellano que fueron aplicadas en las Indias, las costumbres indígenas que fueron incorporadas a dicho sistema ${ }^{13} \mathrm{y}$ las prácticas de aplicación de justicia, que muchas veces no siguieron una ley escrita. El llamado

cuestiones de la historia de Iberoamérica: ensayos y monografías, dir. José Andrés-Gallego (Madrid: Fundación Ignacio Larramendi, 2005) 136.

9. José María García Añoveros, "Luis de Molina y la esclavitud de los negros africanos en el siglo XVI. Principios doctrinales y conclusiones", Revista de Indias 60.219 (2000): 307-329; José Andrés-Gallego, La esclavitud en la América española (Madrid: Ediciones Encuentro, 2005) 48-50.

10. Antonio Manuel Hespanha, Imbecillitas. As bem-aventuranças da inferioridade nas sociedades de Antigo Regime (Sao Paulo / Belo Horizonte: Annablume / Universidade Federal de Minas Gerais, 2010) 136.

11. Beatriz Bernal Gómez, "El derecho indiano, concepto, clasificación y características", Ciencia Jurídica 4.7 (2015): 183-193.

12. Ricardo Levene, Introducción a la historia del derecho indiano (Buenos Aires: Valerio Abeledo, 1924).

13. Miguel Ángel González de San Segundo, "El componente indígena del derecho indiano y la obra de Alfonso García-Gallo", Cuadernos de Historia del Derecho 18 (2011): 211-240, doi: 10.5209/ rev_CUHD.2011.v18.41516; Juan Manzano Manzano, "Las leyes y costumbres indígenas en el orden de prelación de fuentes del derecho indiano", Revista del Instituto de Historia del Derecho Ricardo Levene 18 (1967): 65-71. 
derecho supletorio, es decir, el conjunto de normas que tienen la facultad de regir situaciones que no les son propias por ausencia de normas específicas, estuvo compuesto en parte por la legislación castellana. Evidentemente, el concepto de derecho indiano requiere ser redefinido para abarcar no solo el conjunto normativo producido o adoptado en las Indias, sino también las prácticas de derecho.

Como dice Hespanha, la discusión sobre la esclavitud negra fue tardía con respecto a la indígena. Las leyes de Burgos (1512) y las Nuevas Leyes (1542) se ocuparon de esta última, y esas legislaciones también estaban influenciadas por prácticas precedentes. Las justificativas que perduraron como criterios de la esclavitud indígena fueron las mismas de la "reconquista" y de la esclavitud africana: el lugar de origen, la guerra justa y el rescate. ${ }^{14}$

La legislación más específica para Indias sería reunida a partir de 1680 principalmente en la Recopilación de leyes de los Reinos de las Indias. Este conjunto de leyes conformó un espejo que reflejaba de forma deformada la realidad jurídica americana, y lo que aparece como inconsistencias internas de la recopilación es un reflejo de las diferencias externas. Menciona Tamar Herzog que nada obligaba a las autoridades a adoptar dos veces la misma solución, porque la suposición básica era que cada caso era particular. La ley no se reducía a los códigos. Iglesia, Estado, corporaciones y comunidades se involucraban en enunciar y hacer la ley que nunca fue reducida a códigos legales y ni siquiera a reglas claras. El orden de prelación "recomendado" no era el orden seguido. ${ }^{15}$

La recopilación de las leyes de Indias se deriva de un primer proyecto de Diego de Zorrilla entre 1605 y 1606 y posteriormente tiene su autoría vinculada al Consejo de Indias. Fue un proceso que se extendió por varias décadas y que curiosamente contó con dos proyectos vinculados a la experiencia española en territorio indiano. ${ }^{16} \mathrm{~A}$ pesar de que la obra responde a una necesidad sentida por los administradores coloniales en América, como queda evidenciado en las iniciativas de recopilación de Solórzano Pereira y Pinelo, recoge pocas regulaciones sobre los esclavos negros, como si aquellos no hubieran sentido el "vacío" normativo. Con el título de "derecho de los esclavos" (título XVIII, tomo III) se reúne esencialmente materia fiscal y de comercio sobre las licencias para la introducción de esclavos; la prohibición de que pasen esclavos de Paraguay, Buenos Aires y Tucumán a Perú; el despacho de los navíos de los asientos; la prohibición de que las audiencias se valgan del dinero de los derechos de los esclavos; los contratos entre asentistas y factores; la prohibición de que los navíos de guerra lleven esclavos; la obligatoriedad de que los licenciados portugueses vuelvan a la Casa de Contratación a prestar cuentas después de desembarcar esclavos en las Indias, etcétera. ${ }^{17}$

14. Van Deusen.

15. Tamar Herzog, "Immemorial (and Native) Customs in Early Modernity: Europe and the Americas”, Comparative Legal History 9.1 (2021): 3-55, doi: 10.1080/2049677X.2021.1908930.

16. Alfonso García-Gallo, "La 'Nueva Recopilación de las leyes de Indias' de Solórzano Pereira”, Anuario de Historia del Derecho Español 21-22 (1951-1952): 529-606.

17. Recopilación de las leyes de los reinos de Indias mandadas imprimir y publicar por la Magestad Católica del 
Para Manuel Lucena Salmoral, esa legislación inicial es extremadamente rica y considera al periodo entre 1523 y 1542 como el de configuración de algunas de las temáticas importantes del ordenamiento jurídico sobre los esclavos, tales como las relacionadas con las restricciones a "la introducción de determinados tipos de esclavos, el adoctrinamiento de los negros, los incentivos para mantenerlos sujetos y los castigos a los huidos y cimarrones". ${ }^{18}$ La fecha límite de la periodización de Lucena Salmoral es la de la Leyes Nuevas, pieza fundamental sobre el tratamiento que debía dárseles a los indios.

Si bien esas materias serían muy relevantes para el "gobierno" de los esclavos, el énfasis en ese periodo recae principalmente sobre el campo de la reglamentación del comercio de esclavos. Como se afirma al inicio de este artículo, desde las instrucciones otorgadas al comendador fray Nicolás de Ovando en 1501, la preocupación de los monarcas se concentra en la introducción de esclavos y, en menor medida, en el tratamiento que debía dárseles (las obligaciones de los amos), por lo menos hasta la instrucción sobre educación, trato y ocupaciones de 1789.

El tratamiento de los esclavizados era en gran medida definido en el ámbito de la oikonomia de la tradición grecorromana y no en el de la "economía", esto es, en el de la producción y la circulación de la riqueza de la Ilustración. Así, el mestizaje, las manumisiones y la estratificación entre los esclavos eran producidos en el espacio doméstico, ${ }^{19}$ aunque la monarquía castellana no desistió de interferir en las relaciones entre el pater familias y su “clientela". Regidores, corregidores y, posteriormente, defensores de pobres, de esclavos y síndicos procuradores del bien común evidencian los mecanismos de esa mediación. ${ }^{20}$

En los volúmenes de la recopilación las normativas sobre la esclavitud están esparcidas sin constituir un corpus en sí. Evidentemente, la compilación no podía incluir material sobre el cual las instancias metropolitanas y coloniales habían sido austeras, por no decir omisas, pero es claro que no hay nada que se asemeje a lo que sería el Código Carolino de $1789 .{ }^{21}$ Las Siete Partidas y otros conjuntos normativos castellanos cubrían aspectos sobre lo cotidiano y sobre los derechos de esclavos y amos de forma amplia, y dejaban afuera justamente la materia del tráfico y comercio, tan presente en la legislación para las Indias. En definitiva, las nuevas

Rey Don Carlos II nuestro señor, 4 tomos (Madrid: Boix, 1841).

18. Lucena Salmoral, "Leyes para esclavos" 143.

19. João Fragoso, "Modelos explicativos da chamada economia colonial e a ideia de Monarquia Pluricontinental: notas de um ensaio", História 31.2 (2012): 106-145; Bartolomé Clavero, Antidora. Antropología católica de la economía moderna (Milán: Giuffrè Editore, 1991).

20. Claudia Varella, "El canal administrativo de los conflictos entre esclavos y amos. Causas de manumisión decididas ante síndicos en Cuba”, Revista de Indias 71.251 (2011): 109-136, doi: 10.3989/ revindias.2011.005.

21. Manuel Lucena Salmoral, "El segundo Código negro español, la religión, la humanidad y la tranquilidad y quietud públicas: la crítica realizada en 1788 al Código carolino”, Estudios de Historia Social y Economía de América 12 (1995): 117-131. 
instituciones debían moldarse en las formas antiguas, supliendo los vacíos que estas dejaban con legislación puntual, casuística. ${ }^{22}$

A partir del análisis de diferentes demandas entabladas por los esclavizados en el Río de la Plata a finales del siglo XVIII, es posible afirmar que el fundamento es el de "derechos" inmemoriales, "según el derecho de gentes", sin que haya referencia explícita, por ejemplo, a la real cédula del 31 de mayo de 1789 que recopilaba los derechos de los esclavos. Algunos autores consideran que no fue acatada ${ }^{23} \mathrm{y}$ otros, que abrió espacio para las demandas de los esclavos. ${ }^{24}$ Además, muchas veces los antecedentes locales tenían mayor peso que las leyes generales. Así, cuando fue demandado por su esclavo, el amo Joaquín Manuel Fernández se negó a vender a su siervo al precio que este solicitaba. Dicha interpretación (la de estar obligado a venderlo) era común en Buenos Aires después de la acción de una cautiva de doña Mónica Arce, sin embargo, el señor Fernández no estaba obligado a otorgar la libertad al esclavo que le presentase el valor de su rescate porque eso no constaba en otras piezas del derecho español. ${ }^{25}$

\section{Fuero Juzgo y legislación alfonsí: ¿modeladores de la esclavitud moderna?}

Según Bernardino Bravo Lira, cuando las Siete Partidas fueron introducidas en América, su texto se había estabilizado. Apareció una primera edición con glosa, impresa en Sevilla un año antes del descubrimiento, en 1491. Pero esta, editada por Alonso Díaz de Montalvo, no habría sido la más utilizada en América, sino la de Gregorio López, editada en Salamanca en 1555 y autorizada oficialmente por la real cédula del 7 de septiembre de 1555. Si bien, por el orden de prelación mencionado, las Siete Partidas estaban en tercer lugar en Castilla, después de la legislación real y de los fueros municipales, la materia particular sobre la que versaban hacía que fueran el cuerpo legal de más frecuente aplicación en Castilla y el primero en relación con la esclavitud en Indias, dado el silencio que había al respecto en otras piezas legislativas que le antecedían o que le siguieron. ${ }^{26}$

22. Durante el siglo XVI se emitió una gran cantidad de reales cédulas, ordenanzas y otras piezas legislativas sobre la esclavitud de los indígenas, sobre su prohibición y sobre las excepciones en que era permitida. Pero esta no se mezcla ni se confunde con la otra.

23. Arturo Ariel Betancur y Fernando Aparicio, Amos y esclavos en el Río de La Plata (Buenos Aires: Planeta, 2006).

24. Silvia Mallo, "Experiencias de vida, formas de trabajo y búsqueda de libertad”, Memorias del Simposio La Ruta del Esclavo en el Río de la Plata: su historia y sus consecuencias (Montevideo: UNESCO, 2005) 57-76.

25. María Verónica Secreto, “Justiça na desigualdade: ações de liberdade, 'papéis de venda' e 'justo preço’. Rio da Prata, 1776-1815”, Afro-Ásia 42 (2010): 27-62, doi: 10.9771/aa.v0i42.21209.

26. Bernardino Bravo Lira, "Vigencia de las Partidas en Chile", Revista de Estudios Histórico-Jurídicos 10 (1985): 43-45. 
Las demandas instauradas por los esclavos en diferentes lugares del imperio español, y también en menor medida en la América portuguesa, movilizaron todos los capítulos sobre siervos existentes en las Siete Partidas.

Dice Pierre Vilar que el historiador que observa el funcionamiento de una sociedad pronto percibe que esta tiene reglas cristalizadas en su derecho. Así que la primera tarea es recurrir a sus juristas para conocer los principios de derecho escrito e institucional, luego prestar atención a las costumbres y, por último, observar el nivel de aceptación sociopsicológica.Vilar aún se pregunta si estos síntomas serían suficientes para explicar el funcionamiento de una sociedad y responde que no, porque el principio de funcionamiento de una sociedad no está en su derecho, sino en el hecho socioeconómico que el derecho consagra y organiza sin olvidar que todo modo de producción supone un aparato jurídico que asegura sus reglas. ${ }^{27}$ La esclavización de africanos destinados a América representa una ruptura con la esclavitud medieval. La escala, la función social de esos esclavos, los circuitos comerciales articulados a partir de su tráfico, el impacto demográfico, entre otros factores, indican que se trata de un fenómeno nuevo. Las continuidades deben ser buscadas, tal vez, en la aceptación sociopsicológica de los agentes de la metrópolis para su implementación.

La historiografía sobre la esclavitud reconoce que la legislación alfonsí fue la que rigió las relaciones esclavistas en América, ${ }^{28}$ y no solo en la América hispana, sino que todo el esclavismo moderno habría tenido el influjo de esa legislación precedente. ${ }^{29}$ Una legislación que, originada en el medioevo, reguló las relaciones entre señores y esclavos en la Península Ibérica e influyó en el Mediterráneo. Dentro de esos cuerpos legales, se debe mencionar en primer lugar al Fuero Juzgo, cuyos libros se ocupan en diversos momentos de la figura del siervo y de las situaciones en que este podía encontrarse. Aunque la historiografía reduce la influencia sobre las prácticas esclavas a las Siete Partidas, el Fuero Juzgo es una pieza importante que moldeó prácticas sedimentadas en las costumbres ${ }^{30}$ Este cuerpo legal fue reeditado en Castilla en 1241 y se constituyó inicialmente como traducción del

27. Pierre Vilar, Economía, derecho, historia: conceptos y realidades (Barcelona:Ariel, 1983) 118-120.

28. Manuel Lobo Cabrera, "Las Partidas y la esclavitud: reminiscencias en el sistema esclavista canario”, Publications de l'École Française de Rome 168 (1993): 121-130.

29. María Verónica Secreto, "Asilo: direito de gentes. Escravos refugiados no Império Espanhol", Revista de História 172 (2015): 197-219, doi: 10.11606/issn.2316-9141.rh.2015.98754; Marilyn Stone, "Desde Las Siete Partidas a los códigos civiles norteamericanos", Actas del XI Congreso de la Asociación Internacional de Hispanistas, vol. 3, coord. Juan Villegas (Irvine: Asociación Internacional de Hispanistas, 1994) 25-33.

30. Otros fueros también ejercieron influencia, como el Fors de València (1261). La legitimidad de las capturas en Valencia era corroborada por tribunales que recogían las confesiones de los propios cautivos. Se buscaba confirmar que las capturas hubiesen sido resultado de una guerra justa. Véase Debra Blumenthal, Enemies and Familiars: Slavery and Mastery in Fifteenth-Century Valencia (Ithaca / Londres: Cornell University Press, 2009) 20-21; Francisco Javier Marzal Palacios, "La esclavitud en Valencia durante la Baja Edad Media (1375-1425)" (Tesis de doctorado en Historia Medieval, Universitat de València, 2006) 24. La práctica de la "confesión" de los propios cautivos 
Liber Iudiciorum visigodo del siglo VII. El gobierno de Alfonso X fue continuador de la administración legislativa de su padre Fernando III. Este había confirmado varios fueros locales además de aplicar el Fuero Juzgo en castellano para las comunidades del sur evidenciando el propósito unificador que ganaría nuevos ímpetus con Alfonso X. ${ }^{31}$ Se aplicó como derecho municipal en los territorios conquistados a los musulmanes y estuvo vigente hasta la sanción del Código Civil a fines del siglo XIX.A inicios del siglo XIX, la Real Academia Española realizó una edición y publicación en cuya introducción es posible leer que la misma obedece a que allí estarían los "orígenes" de la lengua, en sus escritos más primitivos, así como a la falta de una edición digna de un código tan antiguo y respetable, pues solo existía una "harto defectuosa hecha en Madrid por Alonso de Villadiego el año de 1600 que se reimprimió en 1792”. La edición con la que se trabajó aquí es la de la Real Academia. ${ }^{32}$

En el siglo XVIII, la traducción del viejo Liber fue utilizada como derecho municipal o local por numerosas localidades andaluzas y murcianas, situada "entre tradiciones"; era fuero, pero un fuero de origen regio que venía de los reyes visigodos y que había sido confirmado por los reyes castellanoleoneses medievales. Prelaciones sucesivas no lo eliminaron. "Si las disposiciones soberanas dejaron de recordarle expresamente desde principios del siglo XIV, ninguna lo abolió, ninguna le derogó, ninguna dijo que se tuviere por no escrito". ${ }^{33}$ Las leyes de la prelación: el Ordenamiento de Alcalá, las Leyes de Toro, la Recopilación, la Novísima Recopilación, todas reiteran y no contradicen el Fuero Juzgo. ${ }^{34}$

Hay dos adjetivaciones (sustantivas) para los hombres en el Fuero Juzgo: libres y siervos. La traducción del Liber Iudiciorum abunda en normativas sobre las obligaciones y deberes de los siervos en relación siempre con los hombres libres, sus señores. Es posible comparar el siervo del código visigodo con el siervo de la legislación alfonsí. Probablemente se trate de una analogía superficial, como dice Marc Bloch al comparar el villainage inglés de los siglos XIII a XV y la servidumbre francesa. "Siervo y villano, ambos son considerados tanto por los juristas como por la opinión común, privados de libertad [...] en fin, precisamente en virtud de esa ausencia de 'libertad', y de ese nombre servil, las personas cultas gustan de asimilarlos a los esclavos romanos". 35 Bloch utiliza el término libertad entre comillas porque agrega que el concepto de no libre ha variado mucho espacial y temporalmente.

también fue utilizada en el Caribe para justificar la esclavitud de los indios antes de 1542. Véase Van Deusen.

31. Marcelo Pereira Lima, "Comparando a fabricação de códigos afonsinos: o Especulo, o Fuero Real e as Siete Partidas", Revista de História Comparada 9.1 (2015): 6-42.

32. Fuero Juzgo en latín y castellano, cotejado con los más antiguos y preciosos códices (Madrid: Ibarra, 1815). Las citaciones del Fuero Juzgo se mantienen fieles al sentido, aunque el vocabulario y la sintaxis fueron actualizados.

33. Los códigos españoles concordados y anotados, t. 1 (Madrid: Imprenta de La Publicidad, 1847) XLVI.

34. Los códigos españoles, t. 1, XLVIII.

35. Marc Bloch, "Pour une histoire comparée des sociétés européennes", Mélanges historiques, t. 1 
Pero la analogía superficial entre el siervo del periodo visigodo y el siervo del siglo XIII esconde una relectura y actualización realizada en el contexto en el que se tradujo el Fuero al castellano, el siglo XIII, y de expansión de la frontera de la cristiandad. Se podría decir que en casi todos los 12 libros que componen el Fuero hay referencias a los siervos y que incluso hay algunos con una incidencia mayor de estas. En esos libros y en sus leyes es posible encontrar algunos de los más importantes antecedentes jurídicos de la esclavitud moderna en las Indias. ${ }^{36}$ También se encontraron leyes de total oposición a la práctica indiana, pero cuya enunciación demuestra la tensión existente desde el siglo VII y el camino normativo de su opuesta formulación. En este caso particular, se hace referencia a leyes como la que prohibía que el mencionado señor fuera obligado a vender su siervo. La prohibición era justificada porque "muchos siervos y muchas siervas huyen a las iglesias a quejarse allí del mal que les hace su señor por lo que los clérigos constriñen los señores a realizar la venta". ${ }^{37}$ Esta disposición es opuesta a la que posteriormente aparecerá en las Siete Partidas como derecho del siervo a cambiar de amo, largamente utilizada en América hispana, ${ }^{38}$ donde la práctica adquiere el nombre del instrumento a través del cual se concreta ese derecho: "papel de venta" o "papel de buscar". La demanda para cambiar de señor se materializaba a través de una autorización en que el amo escribía su nombre, el nombre del esclavo, el domicilio o dirección y el valor que pretendía. Con un papel de esos, los esclavos andaban por las calles buscando una nueva y menos "repugnante" relación de esclavitud. Es posible ver el origen de ese derecho en la práctica de los siervos del siglo VII al XIII y en la mediación eclesiástica. En la América hispana, la mediación fue promovida por los defensores de pobres y regidores. En la historiografia brasileña, dio lugar a un debate incentivado por la antropóloga Manuela Carneiro da Cunha, quien, en la década de 1980, cuestionó

(París: SEVPEN, 1963). Se cita a Marc Bloch aquí, no como un especialista en esclavitud o en villainage, sino más bien como un referente en historia comparada, para reforzar la idea de "analogía superficial". Para la relación entre villainage y esclavitud en el Atlántico anglosajón véase Michael Guasco, Slaves and Englishmen: Human Bondage in the Early Modern Atlantic World (Filadelfia: University of Pennsylvania Press, 2014).

36. Waldomiro Lourenço da Silva Júnior, “Alforria, liberdade e cidadania: o problema da fundamentação legal da manumissão no Antigo Regime ibérico”, Revista de Indias 73.258 (2013): 431-458, doi: 10.3989/revindias.2013.014.

37. Ley XIV,Título IV, Libro V. Fuero Juzgo 87.

38. Alejandro de la Fuente, "Slaves and the Creation of Legal Rights in Cuba: Coartación and Papel", Hispanic American Historical Review 87.4 (2007): 673, doi: 10.1215/00182168-2007039; Secreto, "Justiça na desigualdade". Una real cédula del 19 de abril de 1710 reforzaba la obligatoriedad de la venta en caso de excesos de los señores. "Para que los gobernadores y justicias del Perú y la Nueva España no consientan que con los esclavos ejecuten sus dueños excesos, ni crueldades, ni que los esclavos anden desnudos". Cedulario americano del siglo XVIII. Colección de disposiciones legales indianas desde 1680 a 1800, contenidas en los Cedularios del Archivo General de Indias, t. 3 (Sevilla: Escuela de Estudios Hispano-Americanos de Sevilla / Universidad de Sevilla, 1977) 306-307. 
al viajante Henry Koster (Travels in Brazil, 1816), quien había afirmado que los amos estaban obligados a libertar a sus esclavos cuando ellos ofrecían pagar su valor. Según la autora, era costumbre y no una obligación. Obligación sería solamente, en el Brasil, a partir de la ley de $1871 .{ }^{39}$

La ley XII decía que "si algún siervo se redime de su peguia y el señor no sabía nada de su peguiar, no debe salir del poder de su señor, pues no dio precio por sí mas dio la cosa que era del señor". ${ }^{40}$ Aquí queda establecido que el peculio, aunque se reconocía su existencia, estaba sujeto a la voluntad del señor y era una prerrogativa señorial. Sin embargo, como se verá más adelante, en su conjunto el código es ambiguo y llega a reconocer el derecho del siervo sobre el peculio en circunstancias específicas. En América (tanto española como portuguesa), el peculio tuvo un papel social muy importante en las manumisiones compradas. ${ }^{41}$

El títuloVII del mismo libro V establecía un conjunto de normas para la obtención de la condición de "franqueado". ${ }^{42}$ En primer lugar, la necesidad de testigos para realizar el "franqueamiento", 43 en la ley II se prohibía franquear siervos ajenos y las leyes III y IV abrían uno de los precedentes importantes de las bases jurídicas de los derechos de los esclavos. Si alguien que era tenido por siervo decía que era libre, el juez debía darle espacio y oportunidad para buscar los testigos, y aquel que lo tenía como siervo no podría mantenerlo en su poder durante el proceso. Esta práctica de "custodia" se mantuvo en la América hispana y fue incluida en otros tipos de demandas esclavas, como en las de malos tratos, sevicia, abuso sexual y hasta en procesos de justipreciación. Durante el tiempo que duraba el trámite administrativo o el proceso legal, el esclavo quedaba bajo la custodia de una familia responsable o en una institución de caridad. ${ }^{44}$

39. Manuela Carneiro da Cunha, Antropologia do Brasil: mito, história, etnicidade (Sao Paulo: Brasiliense, 1987).

40. Peguiar, pegujar o peguio, para algunos autores del árabe pugjar. "En nuestro concepto la palabra peguiar y peguio no las tomamos de los árabes, sino que las romanceamos del ablativo de la voz latina peculio, según se infiere del mismo código. El origen de la palabra peculio es bien conocido, pecunia; y el de esta, pecus, que debe estimarse como primitiva, raíz y fuerte de todas las anteriores y antiquísima entre los romanos". León Galindo y de Vera, Proceso y vicisitudes del idioma castellano en nuestros cuerpos legales desde que se romancé el Fuero Juzgo hasta la sanción del Código Penal que rige en España (Madrid: Imprenta Nacional, 1863) 49-50; Fuero Juzgo 88.

41. Manolo Florentino, "Alforrias e etnicidade no Rio de Janeiro oitocentista: notas de pesquisa", Topoi 3.5 (2002): 9-40.

42. "Franqueado, da. part. pass. del verbo Franquear en sus acepciones. Latín. Exemptus. Patefactus. FUER. R. lib. 2. tit. 1. 1. 3. Si el señor franqueare su siervo, sin precio que él dé, y el franqueado muriere sin hijos legítimos y sin manda, aquel que lo franqueó, o sus herederos hayan toda su buena". "Franco. Vale tambien desembarazado, libre, y sin impedimento alguno. Latín. Expeditus. Liber. CERV. Quix. tom. 2. cap. 56. Que se contentasse con que le daba campo franco en su tierra; puesto que iba contra el decreto del Santo Concílio, que prohibe los tales desafios". Diccionario de Autoridades, t. 3 (Madrid: Real Academia Española, 1732).

43. Fuero Juzgo 94.

44. AGN, Buenos Aires, División Colonia, Tribunales, Sala IX, leg. 23-8-6; AGN, Buenos Aires, Administrativos, Sala IX, 23-6-3, leg. 15, exp. 440. 
Las leyes visigodas sobre el franqueo echaron los cimientos de la condicionalidad de la libertad y de la gratitud exigida a los ahorrados. Entre las leyes IX y XII se estipulaba que el siervo franqueado podría volver a la servidumbre en caso de deshonrar o denostar a su antiguo señor, de hacerle algún mal o de testimoniar contra él o contra sus hijos y linaje. Las leyes siguientes avanzaban aún más en las limitaciones de los esclavos liberados; estas se referían a las obligaciones materiales que los mismos debían guardar con sus antiguos señores, ${ }^{45}$ y en la ley XIV emerge un precedente sobre el derecho al peculio. Si bien al inicio de las leyes sobre franqueo el peculio aparece como potestad señorial, ya que definía que el franqueamiento del siervo realizado con un peculio que no fuera del conocimiento del señor no era válido porque había utilizado algo que no era del esclavo sino del señor, en esta ley XIV "De las condiciones que pone el señor cuando franquea el siervo", se establece que si el señor no definió las condiciones para el uso del peculio al momento de franquear a su siervo, este podría utilizar de él como mejor entendiera. ${ }^{46}$ Asimismo, la ley XV evidencia la existencia de siervos que son poseedores de siervos y otras propiedades.

En el título IV del libro V se encontró una ley que merece ser destacada: una de las formas de entrar en servidumbre era la venta de sí mismo. Un hombre libre podía venderse para pagar una deuda y esta era una forma legítima de esclavitud. La ley en cuestión señala que si "aquel que se vendió o se dejó vender pudiera pagar el precio por redimirse, o sus padres lo pagaran por él a aquel que lo compró, el comprador debe recibir el precio y aquel otro debe ser libre". ${ }^{47}$ Es muy larga la lista de autores que afirman que no existió tal ley y que la práctica de comprar la propia libertad, así como la "supuesta" obligatoriedad del amo a otorgarla en caso de que el esclavo presentase el valor que había sido pagado por él, no se basó en ningún texto legal, sino que dicha práctica en las Indias se debió a la difusión de una costumbre. En este caso, como en otros, es interesante observar que el origen de la ley escrita se pierde en la práctica. Probablemente los magistrados, jueces, regidores que otorgaron el beneficio de la libertad en la forma de "la compra de sí", o de

45. Roberto Guedes, "Porque sempre é bom que os forros tenham quem olhe por eles. Benignidade senhorial e libertos submissos na cidade do Rio de Janeiro (primeira metade do século XVIII)", Formas de liberdade. Gratidão, condicionalidade e incertezas no mundo escravista nas Américas, orgs. Jonis Freire y María Verónica Secreto (Río de Janeiro: Mauad / Fundação Carlos Chagas Filho de Amparo à Pesquisa do Estado do Rio de Janeiro, 2018) 177-210; Magdalena Candioti, "Manumisiones negociadas y libertades frágiles en el Río de la Plata. Santa Fe, 1810-1853", Formas de liberdade. Gratidão, condicionalidade e incertezas no mundo escravista nas Américas, orgs. Jonis Freire y María Verónica Secreto (Río de Janeiro: Mauad / Fundação Carlos Chagas Filho de Amparo à Pesquisa do Estado do Rio de Janeiro, 2018) 129-155.

46. Fuero Juzgo 97.

47. Fuero Juzgo 97. Con esto no se pretende decir que esta fue la ley por la cual se entendió en América que existía el derecho de un esclavo a comprar su libertad al pagar su precio de compra al amo. Como afirma Lucena Salmoral, ni ese ni el derecho a tener peculio fueron regulados. Véase Manuel Lucena Salmoral, "El derecho de coartación del esclavo en la América Española”, Revista de Indias 59.216 (1999): 360. 
aquellos que la demandaban representados por los defensores de pobres, lo hayan hecho siguiendo algo que entendían como costumbre o como ley local. Solo más investigaciones empíricas que arrojen luz sobre las demandas y casos que tuvieron lugar en tribunales, cabildos y audiencias podrán corroborar fehacientemente la relación entre los códigos medievales y las prácticas indianas.

\section{Sujetos sin libertad: siervos y cautivos}

Si el Fuero Juzgo recoge la voz "siervo", no ocurre lo mismo con la de "cautivo", presente en la legislación alfonsí, aunque algunos trabajos optan por la asimilación de un vocablo al otro. Tal es el caso del trabajo de Marzal Palacios. ${ }^{48}$ Para los fines de este trabajo, es menester separarlos para entender mejor cómo se fueron constituyendo la legislación, la jurisprudencia y las prácticas indianas sobre el esclavo. El Diccionario de Autoridades de 1729 registra en las entradas "cautivo" y "siervo" las siguientes definiciones:

Cautivo. s. m. Lo mismo que Captivo. Latín. Captivus. RECOP. lib. 1. tit. 11. 1. 1. Porque los nuestros vassallos y naturales, que están cautívos en tierra de Moros ... mas prestamente se puedan rescatar. MARIAN. Hist. Esp. lib. 3. cap. 4. Los despojos que ganó fueron ricos, los cautívos en gran número. ${ }^{49}$

Siervo, va. adj. Lo mismo que esclavo. Viene del Latino Servus. FUER. JUZG. lib. 4. tit. 5. 1. 1. Mandamos que si alguno era siervo en tiempo, que fizo el mal: maguer, que en el tiempo de la sentencia sea ahorrado, à tal pena haya como manda la ley, que dén à siervo. CALIST.Y MELIB. f. 7. Impossible es hacer siervo diligente el amo perezoso..$^{50}$

En la definición del siglo XVIII, "esclavo" y "cautivo" aluden a estatutos diferentes, aunque esclavo y siervo son consideradas sinónimos. En América esa diferencia lexical se mantendrá. La literatura sobre el cautiverio americano es muy extensa, y comienza con las propias crónicas de los conquistadores y los testimonios de los cautivos. ${ }^{51}$ Los dos términos fueron utilizados para definir en América situaciones semejantes a las que definían en la Península Ibérica, o por lo menos situaciones que eran entendidas como semejantes. Así, el término "cautivo" en

48. Marzal Palacios 99-100.

49. Diccionario de Autoridades, t. 2 (Madrid: Real Academia Española, 1729). http://web.frl.es/ DA.html (0 3/09/2021).

50. Diccionario de Autoridades, t. 6 (Madrid: Real Academia Española, 1739). http://web.frl.es/ DA.html (03/09/2021).

51. Horacio Zapater Equioiz, “Testimonio de un cautivo. Araucanía, 1599-1614”, Historia 23 (1988): 295-325. Las crónicas y relatos de cautivos son muchos, este caso además de narrar la experiencia personal, nos ofrece un cuadro de la importancia del cautivo en la sociedad receptora. En su declaración Fray Juan Falcón informa de la existencia de unos 200 españoles y unas trescientos cincuenta españolas en la situación de cautiverio, que servían a los indios como "esclavos". 
América fue utilizado para la relación entre cristianos y no cristianos en la frontera de "evangelización", mientras que "esclavo" se usó para quien permaneciera privado de la libertad entre los cristianos al llegar a las Indias o nacer en ellas. Dice Luiz Felipe de Alencastro que, en el vocabulario indoeuropeo en general, "cautivo" define al individuo hecho prisionero, en poder de su captor o traficante. En los idiomas de los pueblos de África occidental, central y oriental, de donde provenían los esclavizados traficados por Portugal, había palabras con significados diferentes para cautivo y esclavo. La literatura barroca relativizó la contingencia de la libertad humana, instalando la identidad de significado entre las dos palabras en la lengua portuguesa (una de las principales lenguas del tráfico esclavista). El diccionario de Bluteau que codificó el portugués del siglo XVII, aún guardó las diferencias sociales y jurídicas entre cautivo y esclavo. ${ }^{52}$

El Fuero Juzgo no menciona la palabra “cautivo". Es posible atribuir esa ausencia al hecho de haber sido compuesto antes de la presencia musulmana en la península, esto es, antes de que una amplia frontera determinara un dentro y fuera del cristianismo y de que el cautiverio se transformara en una práctica que mediaba las relaciones entre cristianos y no cristianos. La figura del siervo lo engloba todo en aquella tradición.

La guerra entre cristianos y musulmanes en la España medieval fue una de las vías para la obtención de botines y rescates. La frontera en constante cambio fue el escenario de las cabalgatas y expediciones en los dos sentidos: de los territorios moros hacia los cristianos y viceversa. La captura de prisioneros constituyó una de las "riquezas" que fue pasando de un territorio a otro. La captura y comercialización de los prisioneros requirió de un tratamiento jurídico y un ordenamiento que estableciera claramente los derechos y deberes de ellos, así como los mecanismos del rescate. En tal sentido, a los fueros municipales hay que agregar la legislación de Alfonso X, el Sabio, especialmente las Partidas. ${ }^{53}$

En las Partidas aparecen dos personas que carecen de libertad, el siervo y el cautivo, y aunque ya se vio que pueden ser tratados como sinónimos, no lo son, y así también lo entiende la legislación de la Alta Edad Media. Las Partidas tratan de ellos en libros diferentes. En la Segunda Partida, el título XXIX, llamado "De los cautivos y de sus cosas", se ocupa de definir los derechos sobre los bienes de los cautivos, "sus cosas". Determina en su ley I lo que se entiende por "cautivo" y "preso". ${ }^{54}$ En resumen, los "presos" son quienes no tienen otra penalidad que la de su prisión, la de sus cuerpos. Y si se le aprende algún bien es para compensar los gastos que se hayan hecho en el tiempo de su prisión. Por otra parte, los "cautivos" son quienes caen en prisión de hombres de otra creencia. Estos son atormentados

52. Luiz Felipe de Alencastro, O trato dos viventes. Formação do Brasil no Atlântico Sul. Séculos XVI e XVII (Sao Paulo: Companhia das Letras, 2000) 88.

53. Francisco Javier Díaz González, "La normativa sobre los prisioneros y los cautivos en la España cristiana medieval", Revista de Estudios Histórico-Jurídicos 32 (2010): 281-308.

54. Las Siete Partidas del Rey Don Alfonso el Sabio, cotejadas con varios códices antiguos por la Real Academia de la Historia, t. 2 (Madrid: Imprenta Real, 1807) 327. 
con crudas penas y hasta son vendidos o asesinados. "Sacar los hombres de cautiverio es cosa que place mucho a Dios porque es obra de piedad y de merced, y está bien en este mundo a los que lo hacen". ${ }^{55}$ Las Partidas establecen quiénes están obligados a socorrer a los cautivos: los de la misma fe, los de mismo linaje, los vinculados por vasallaje; por amor de voluntad. Pero si el cautivo no fuera rescatado y muriera en esa condición, sus bienes debían ser vendidos y destinados al rescate de otros cautivos, porque sus bienes no deben ser heredados por aquellos que lo dejaron morir en cautiverio. ${ }^{56}$

Toda la legislación sobre cautivos tenía como propósito la preservación de los derechos de los cristianos en poder de los moros, así como la conservación de los bienes de unos y otros, inclusive de los moros para que pudieran pagar por sus rescates. Por eso el título siguiente a "De los cautivos y de sus cosas" es "De los Alfaqueques", esto es, de los hombres de bien destinados al rescate de los cristianos. Las Siete Partidas describen y establecen las características de la actividad del rescate y de sus ejecutores.

Del rescate de cristianos se tienen varios registros. Pero ¿qué ocurría en el otro sentido?, ¿qué se sabe sobre la condición de cautiverio de los moros? Para los fines de este trabajo, son ellos quienes interesan. De las aprehensiones realizadas en guerra, es decir, de los moros que eran tomados como prisioneros en el asalto de alguna ciudad, en incursiones al sur de la Península Ibérica o por el norte de África, no todos terminaban siendo siervos. Es posible afirmar, como se ha hecho a lo largo de este trabajo, que "siervo" y "cautivo" son dos estatutos jurídicos diferentes. Los cautivos podían terminar siendo siervos si no hubieran sido rescatados. ${ }^{57}$ Los cautivos que no tenían dinero para redimirse ni eran redimidos por algún correligionario acababan siendo vendidos en almoneda pública. ${ }^{58}$ Aun en esta condición, podían tener la suerte de ser comprados por un mudéjar, como lo observa Marzal Palacios al referirse a los sarracenos de Valencia entre 1375 e 1425: "Si la manumisión por el propietario y la liberación en testamento les estaban "vetadas" (de forma clara la segunda, con algunas reservas la primera), este tipo de esclavos contaba por el contrario con otras vías a su alcance para recuperar la libertad. Esta vía hacia la libertad se concreta en la adquisición por un mudéjar valenciano, o por varios en su caso, de un esclavo sarraceno". ${ }^{59}$ El autor apunta que es una venta como cualquier otra, solo que tiene como finalidad la liberación del esclavo en cuestión.

Según González Arévalo, el tiempo de pasaje de "cautivo a esclavo" era de aproximadamente seis meses. Si en ese tiempo el cautivo no era rescatado, entonces sería

55. Las Siete Partidas, t. 2, 327.

56. Las Siete Partidas, t. 2, 328.

57. Ana Echevarría Arsuaga, "Esclavos musulmanes en los hospitales de cautivos de la Orden Militar de Santiago (siglos XII y XIII)", Al-Qantara 28.2 (2007): 465-488, doi: 10.3989/alqantara.2007. v28.i2.45

58. Raúl González Arévalo, "Cautivos moros y judíos en Málaga en tiempo de los Reyes Católicos", Baetica. Estudios de Historia Moderna y Contemporánea 27 (2005): 345-361.

59. Marzal Palacios 1150 y ss. 
vendido como esclavo en almoneda pública a precio de mercado, lo que podía facilitar el "rescate" dentro de la comunidad mudéjar. Las cantidades pagadas por los rescates, cuando se concertaban con cada uno de los cautivos, eran mucho más altas que los precios de "mercado". La toma de cautivos y su rescate era una actividad económica importante.

Cuando las instrucciones del comendador fray Nicolás de Ovando fueron emitidas en 1501, las dos tradiciones de "sujetos sin libertad" que existían en la Península Ibérica eran la de los cautivos y la de los siervos o esclavos. La primera, con énfasis en la "transitoriedad" y en la realización de un valor monetario, y la segunda, con énfasis en la propiedad y en la apropiación del trabajo.

Si bien la esclavitud ocupa buena parte de las reflexiones del pensamiento occidental desde la antigüedad, fue en el momento en que los portugueses recorren, penetran y conquistan territorios africanos, y que Castilla pone sus pies en Indias, cuando el debate entre teólogos y canonistas se intensifica. Cabe preguntarse hasta qué punto la tradición del cautiverio influyó en la de la esclavitud moderna. El principio de rescate estaba consagrado en las Siete Partidas a partir de la fórmula: "Sacar los hombres de cautiverio es cosa que place mucho a Dios porque es obra de piedad y de merced, y está bien en este mundo a los que lo hacen" ${ }^{60}$

En 1735, la compañía inglesa que proveía de esclavos a las posesiones españolas desembarcó un cargamento de hombres, mujeres y niños esclavizados provenientes del Congo en el puerto de Cartagena de Indias. Todos traían marcada una cruz en el pecho, lo que provocó mucha impresión en los cartageneros. Este caso despertó dudas en el gobernador, quien escribió al rey pidiendo instrucciones, pues entendía que los cristianos no podían ser esclavizados. Lucena Salmoral, al analizar este caso, destaca el carácter original del parecer del fiscal consultado por el rey y por el Consejo de Indias. ${ }^{61} \mathrm{El}$ fiscal respondió retomando algunos principios de la esclavitud hispana, como el hecho de que los cristianos no pueden ser esclavos de infieles o herejes. Por ello, recomendaba que los esclavos llegados en tan particulares condiciones no fueran devueltos a los ingleses (herejes), sino que, como cualquier cristiano rescatado, debían devolver el precio de su rescate. Los esclavos (ahora rescatados) deberían devolver a sus señores lo que estos habían desembolsado en su compra, lo que, a partir de ese dictamen, se transformó en valor pago por el rescate.

Comenta Hespanha que, cuando Luis de Molina escribió su tratado sobre esclavitud africana (c. 1593), no le bastó una respuesta que la justificara en términos del derecho positivo europeo. Ese derecho solo podría dar respuesta sobre cómo los europeos convertían hombres libres en esclavos (por vía de guerra justa o por condena penal). Él precisaba de una respuesta que incluyera la situación de compra

60. Las Siete Partidas 327. Sobre las "facilidades" para el rescate de cautivos véase James William Brodman, "Captives or Prisoners: Society and Obligation in Medieval Iberia", Anuario de Historia de la Iglesia 20 (2011): 201-219.

61. Manuel Lucena Salmoral, Regulación de la esclavitud negra en las colonias de América Española (15031886). Documentos para su estudio (Alcalá de Henares / Murcia: Universidad de Alcalá / Universidad de Murcia, 2005) 129-130. 
de alguien ya esclavizado. ¿Cómo saber si la esclavización había sido legítima? La compra no constituía un título originario sino derivado. El vendedor ofrecía no una cosa, sino unos derechos: "Era, antes, um título meramente derivado, pressupondo uma anterior situação de escravidão e não transferindo para o comprador senão os exato direitos do vendedor". ${ }^{6}$

Una real cédula del 23 de octubre de 1736 ordenó la permanencia de los esclavos en las manos de sus compradores, como siervos rescatados y en calidad de deudores. El rey alertaba sobre el problema abierto y la necesidad de consultar a una junta de teólogos, ya que la South Sea Company, al no conseguir vender más esclavos cristianos al príncipe católico, los vendería a herejes, lo que evidentemente agravaba el problema espiritual y terrenal. ${ }^{63}$

El término "rescate" se impuso en las Indias. La documentación española lo utilizó largamente como sinónimo de "trata", y no lo hizo por pudor, como creía Fernando Ortiz: "De todos modos acaso por pudor jurídico el rey Fernando II en la Real Cédula de 12 de diciembre de 1619 llamaba a la trata negrera de rescate de esclavos negros". ${ }^{64}$

La terminología de la Edad Media lo contaminó todo y las prácticas medievales también. España mezcló las experiencias. ${ }^{65}$ Entre los años 1623 y 1690, el Consejo de Indias emitió reales cédulas en las que se autorizaba a diferentes individuos a pedir limosna en las Indias durante cuatro años para rescatar parientes cautivos en Argel y el fondo de rescate era distribuido para recuperar cristianos en Fez, en Argel, e indios y cristianos capturados por los moros y vendidos a los holandeses en Filipinas. ${ }^{66}$ España rebasa su territorio y, en poco más de un siglo, se crea una red "global" de rescates.

\section{Hespanha 139.}

63. Cedulario americano, t. 3, 191-192.

64. Fernando Ortiz, Hampa afro-cubana. Los negros esclavos. Estudio sociológico y de derecho público (Habana: Revista Bimestre Cubana, 1916) 337.

65. Serge Gruzinski, “Os mundos misturados da monarquia católica e outras connected histories”, Topoi 2.2 (2001): 175-195.

66. "Real cédula concediendo licencia a Francisco Fernández de las Roelas, para pedir limosna en Indias durante 4 años, para el rescate de su hermano Martín de Roelas, preso de moros en Argel”, 1629. AGI, Sevilla, Indiferente, 433, leg. 4, ff. 239v-240v; "Real Cédula dando licencia a Amaro Mandaño para pedir limosna en Indias para el rescate de dos hermanos suyos cautivos en Argel”, 1670. AGI, Sevilla, Indiferente, 430, leg. 41, ff. 205v-206r; "Real Cédula dando licencia a Diego Gómez de León para pedir limosna en Indias para el rescate de un hermano suyo que está cautivo en Argel", 1666. AGI, Sevilla, Indiferente, 430, leg. 41, ff. 110v-111v; "Real Cédula dando licencia a Juna Marín para pedir limosna en Indias para el rescate de su padre y su hermano cautivos de los moros", 1674. AGI, Sevilla, Indiferente, 430, leg. 41, ff. 337r- 337v; "Real Cédula dando licencia para que en una feria de flota de Portobelo se pueda pedir limosna para ayudar al rescate de Juan Guerrero, cautivo en Argel”, 1690. AGI, Sevilla, Indiferente, 431, leg. 43, ff. 171v-172v. En 1713 el rey FelipeV emitió una real cédula sobre como deberían ser remitidos los caudales de las limosnas destinadas al rescate de los cautivos. Cedulario americano del siglo XVIII. Colección de disposiciones legales indianas desde 1680 a 1800 contenidas en los cedularios del Archivo General de Indias, t. 2 (Sevilla: Escuela de Estudios Hispano-Americanos de Sevilla / Universidad de Sevilla, 1977) 351-352. 


\section{Conclusión}

Como afirma Bravo Lira, en el tiempo de la conquista de América, el texto de las Siete Partidas estaba estabilizado. Los códigos recopilados por Fernando III y Alfonso X se habían decantado. En la práctica, sobre todo del lado de la demanda, las Partidas son mencionadas recurrentemente, en especial, en las demandas de los esclavos, y algunas veces en las sentencias de los jueces. La nueva realidad fue pensada por analogía a partir del mundo conocido y posteriormente como realidad nueva a ser normativizada, contenida y regulada. La realidad indiana desafió al jurista, al canonista, al teólogo. Pero también a los gremios y a las comunidades. Los cuerpos jurídicos expresan sin sintetizar, condensan, comprimen siglos, culturas y experiencias diferentes y plásticas. Mas aún, muchas cosas se les escapan; no pueden ser aprendidas por los códigos, las leyes escritas, las ordenanzas, etcétera.

En este artículo se busca evidenciar que las primeras medidas tomadas por la Corona con respecto a los esclavos fueron las de regular su introducción, entendiendo en esa primerísima instancia las islas y Tierra Firme del Mar Océano como "una experiencia controlada" en que la ausencia de judíos, herejes, reconciliados y cristianos nuevos era necesaria para crear una versión mejorada de la cristiandad hispana. En la medida en que la empresa colonial se desarrolla y que adelantados, capitanes generales y demás integrantes de la hueste indiana demandan la introducción de esclavos negros, se suceden las capitulaciones que incluyen ese privilegio. España introduce la esclavitud de africanos en América y con ella las tradiciones peninsulares que se arrastrarían por los próximos siglos en los diferentes dominios de las potencias coloniales. La idea de una "experiencia controlada" se torna una ficción. La realidad desborda lo imaginado.

Es evidente que las leyes medievales ejercieron influencia sobre la esclavitud moderna. La primera potencia colonial en introducir esclavos en América también introdujo la tradición jurídica y normativa con que serían gobernados. Introdujo la diferenciación entre tráfico y esclavitud sin conseguir participar del primero.

\section{Fuentes}

\section{Manuscritas}

Archivo General de Indias, Sevilla (AGI)

Indiferente

Archivo General de la Nación, Buenos Aires (AGN)

División Colonia

Administrativos 


\section{Impresas}

Aranda, Ricardo. Colección de los tratados, convenciones, capitulaciones, armisticios y otros actos diplomáticos y políticos celebrados desde la Independencia hasta el día. Tomo 1. Lima: Imprenta del Estado, 1890.

Cedulario americano del siglo XVIII. Colección de disposiciones legales indianas desde 1680 a 1800, contenidas en los Cedularios del Archivo General de Indias. Tomo 3. Sevilla: Escuela de Estudios Hispano-Americanos de Sevilla / Universidad de Sevilla, 1977.

Fuero Juzgo en latín y castellano, cotejado con los más antiguos y preciosos códices. Madrid: Ibarra, 1815.

Galindo y de Vera, León. Proceso y vicisitudes del idioma castellano en nuestros cuerpos legales desde que se romanceó el Fuero Juzgo hasta la sanción del Código Penal que rige en España. Madrid: Imprenta Nacional, 1863.

Las Siete Partidas del Rey Don Alfonso el Sabio, cotejadas con varios códices antiguos por la Real Academia de la Historia. Tomo 2. Madrid: Imprenta Real, 1807.

Los códigos españoles concordados y anotados. Tomo 1. Madrid: Imprenta de La Publicidad, 1847.

Recopilación de las leyes de los reinos de Indias mandadas imprimir y publicar por la Magestad Católica del Rey Don Carlos II nuestro señor. 4 Tomos. Madrid: Boix, 1841.

\section{Internet}

www.cervantesvirtual.com (2005).

\section{Bibliografía}

Aguirre Beltrán, Gonzalo. La población negra de México. Estudio etnohistórico. México: Fondo de Cultura Económica, 1972.

Andrés-Gallego, José. La esclavitud en la América española. Madrid: Ediciones Encuentro, 2005.

Assadourian, Carlos Sempat. El tráfico de esclavos en Córdoba de Angola a Potosí. Siglos XVI-XVII. Córdoba: Dirección General de Publicaciones, 1966. . El tráfico de esclavos en Córdoba, 1588-1610, según las actas de protocolos del Archivo Histórico de Córdoba. Córdoba: Dirección General de Publicaciones, 1965.

Betancur, Arturo Ariel y Fernando Aparicio. Amos y esclavos en el Río de La Plata. Buenos Aires: Planeta, 2006.

Bernal Gómez, Beatriz. "El derecho indiano, concepto, clasificación y características". Ciencia Jurídica 4.7 (2015): 183-193.

Bloch, Marc. "Pour une histoire comparée des sociétés européennes". Mélanges historiques. Tomo 1. París: SEVPEN, 1963.

Blumenthal, Debra. Enemies and Familiars: Slavery and Mastery in Fifteenth-Century Valencia. Ithaca / Londres: Cornell University Press, 2009. 
Bravo Lira, Bernardino. "Vigencia de las Partidas en Chile". Revista de Estudios Histórico-Jurídicos 10 (1985): 43-105.

Brodman, James William. "Captives or Prisoners: Society and Obligation in Medieval Iberia". Anuario de Historia de la Iglesia 20 (2011): 201-219.

Candioti, Magdalena. "Manumisiones negociadas y libertades frágiles en el Río de la Plata. Santa Fe, 1810-1853”. Formas de liberdade. Gratidão, condicionalidade e incertezas no mundo escravista nas Américas. Orgs. Jonis Freire y María Verónica Secreto. Río de Janeiro: Mauad / Fundação Carlos Chagas Filho de Amparo à Pesquisa do Estado do Rio de Janeiro, 2018.

Carneiro, Manuela da Cunha. Antropologia do Brasil: mito, história, etnicidade. Sao Paulo: Brasiliense, 1987.

Clavero, Bartolomé. Antidora. Antropología católica de la economía moderna. Milán: Giuffrè Editore, 1991.

Córtes López, José Luis. Carlos I y el comercio de esclavos. Alicante: Biblioteca Virtual Miguel de Cervantes, 2001.

Da Silva Júnior, Waldomiro Lourenço. “Alforria, liberdade e cidadania: o problema da fundamentação legal da manumissão no Antigo Regime ibérico”. Revista de Indias 73.258 (2013): 431-458. Doi: 10.3989/revindias.2013.014.

De Alencastro, Luiz Felipe. O trato dos viventes. Formação do Brasil no Atlântico Sul. Séculos XVI e XVII. Sao Paulo: Companhia das Letras, 2000.

De la Fuente, Alejandro. "Slaves and the Creation of Legal Rights in Cuba: Coartación and Papel". Hispanic American Historical Review 87.4 (2007): 659-692. Doi: 10.1215/00182168-2007-039.

Díaz González, Francisco Javier. "La normativa sobre los prisioneros y los cautivos en la España cristiana medieval". Revista de Estudios Histórico-Jurídicos 32 (2010): 281-308.

Echevarría Arsuaga, Ana. "Esclavos musulmanes en los hospitales de cautivos de la Orden Militar de Santiago (siglos XII y XIII)”. Al-Qantara 28.2 (2007): 465-488. Doi: 10.3989/alqantara.2007.v28.i2.45.

Florentino, Manolo. "Alforrias e etnicidade no Rio de Janeiro oitocentista: notas de pesquisa". Topoi 3.5 (2002): 9-40.

Fragoso, João. "Modelos explicativos da chamada economia colonial e a ideia de Monarquia Pluricontinental: notas de um ensaio”. História 31.2 (2012): 106-145.

García Añoveros, José María. "Luis de Molina y la esclavitud de los negros africanos en el siglo XVI. Principios doctrinales y conclusiones". Revista de Indias 60.219 (2000): 307-329.

García-Gallo, Alfonso. “La 'Nueva Recopilación de las leyes de Indias' de Solórzano Pereira”. Anuario de Historia del Derecho Español 21-22 (1951-1952): 529-606.

González Arévalo, Raúl. "Cautivos moros y judíos en Málaga en tiempo de los Reyes Católicos”. Baetica. Estudios de Historia Moderna y Contemporánea 27 (2005): 345-361. 
González de San Segundo, Miguel Ángel. “El componente indígena del derecho indiano y la obra de Alfonso García-Gallo". Cuadernos de Historia del Derecho 18 (2011):211-240. Doi: 10.5209/rev_CUHD.2011.v18.41516.

Gruzinski, Serge. "Os mundos misturados da monarquia católica e outras connected histories”. Topoi 2.2 (2001): 175-195.

Guasco, Michael. Slaves and Englishmen: Human Bondage in the Early Modern Atlantic World. Filadelfia: University of Pennsylvania Press, 2014.

Guedes, Roberto. "Porque sempre é bom que os forros tenham quem olhe por eles. Benignidade senhorial e libertos submissos na cidade do Rio de Janeiro (primeira metade do século XVIII)". Formas de liberdade. Gratidão, condicionalidade e incertezas no mundo escravista nas Américas. Orgs. Jonis Freire y María Verónica Secreto. Río de Janeiro: Mauad / Fundação Carlos Chagas Filho de Amparo à Pesquisa do Estado do Rio de Janeiro, 2018.

Herzog, Tamar. "Immemorial (and Native) Customs in Early Modernity: Europe and the Americas". Comparative Legal History 9.1 (2021): 3-55. Doi: 10.1080/2049677X.2021.1908930.

Hespanha, Antonio Manuel. Imbecillitas. As bem-aventuranças da inferioridade nas sociedades de Antigo Regime. Sao Paulo / Belo Horizonte: Annablume / Universidade Federal de Minas Gerais, 2010.

Kamen, Henry. "El negro en Hispanoamérica 1500-1700". Anuario de Estudios Americanos 28 (1971): 121-137.

Ricardo Levene. Introducción a la historia del derecho indiano. Buenos Aires: Valerio Abeledo, 1924.

Lima, Marcelo Pereira. "Comparando a fabricação de códigos afonsinos: o Especulo, o Fuero Real e as Siete Partidas". Revista de História Comparada 9.1 (2015): 6-42.

Lobo Cabrera, Manuel. "Las Partidas y la esclavitud: reminiscencias en el sistema esclavista canario”. Publications de l'École Française de Rome 168 (1993): 121-130.

Lucena Salmoral, Manuel. "El segundo Código negro español, la religión, la humanidad y la tranquilidad y quietud públicas: la crítica realizada en 1788 al Código carolino”. Estudios de Historia Social y Economía de América 12 (1995): 117-131.

. "El derecho de coartación del esclavo en la América Española". Revista de Indias 59.216 (1999): 357-374.

. "Leyes para esclavos. El ordenamiento jurídico sobre la condición, tratamiento, defensa y represión de los esclavos en las colonias de la América española”. Tres grandes cuestiones de la historia de Iberoamérica: ensayos y monografías. Dir. José Andrés-Gallego. Madrid: Fundación Ignacio Larramendi, 2005.

. Regulación de la esclavitud negra en las colonias de América Española (15031886). Documentos para su estudio. Alcalá de Henares / Murcia: Universidad de Alcalá / Universidad de Murcia, 2005. 
Mallo, Silvia. "Experiencias de vida, formas de trabajo y búsqueda de libertad". Memorias del Simposio La Ruta del Esclavo en el Río de la Plata: su historia y sus consecuencias. Montevideo: UNESCO, 2005.

Manzano Manzano, Juan. "Las leyes y costumbres indígenas en el orden de prelación de fuentes del derecho indiano”. Revista del Instituto de Historia del Derecho Ricardo Levene 18 (1967): 65-71.

Marzal Palacios, Francisco Javier. "La esclavitud en Valencia durante la Baja Edad Media (1375-1425)". Tesis de doctorado en Historia Medieval, Universitat de València, 2006.

Ortiz, Fernando. Hampa afro-cubana. Los negros esclavos. Estudio sociológico y de derecho público. Habana: Revista Bimestre Cubana, 1916.

Rumeu de Armas, Antonio. La política indigenista de Isabel la Católica. Valladolid: Instituto "Isabel la Católica" de Historia Eclesiástica, 1969.

Secreto, María Verónica. “Asilo: direito de gentes. Escravos refugiados no Império Espanhol”. Revista de História 172 (2015): 197-219. Doi: 10.11606/ issn.2316-9141.rh.2015.98754.

. "Justiça na desigualdade: ações de liberdade, 'papéis de venda' e 'justo preço’. Rio da Plata, 1776-1815”. Afro-Ásia 42 (2010): 27-62. Doi: 10.9771/aa.v0i42.21209.

Stone, Marilyn. "Desde Las Siete Partidas a los códigos civiles norteamericanos". Actas del XI Congreso de la Asociación Internacional de Hispanistas. Volumen 3. Coord. Juan Villegas. Irvine:Asociación Internacional de Hispanistas, 1994.

Van Deusen, Nancy E. Global Indios: The Indigenous Struggle for Justice in SixteenthCentury Spain. Durham / Londres: Duke University Press, 2015.

Varella, Claudia. "El canal administrativo de los conflictos entre esclavos y amos. Causas de manumisión decididas ante síndicos en Cuba". Revista de Indias 71.251 (2011): 109-136. Doi: 10.3989/revindias.2011.005.

Vila Vilar, Enriqueta. "Los asientos portugueses y el contrabando de negros". Anuario de Estudios Americanos 30 (1973): 557-609.

Vilar, Pierre. Economía, derecho, historia: conceptos y realidades. Barcelona: Ariel, 1983.

Zapater Equioiz, Horacio. "Testimonio de un cautivo, Araucanía, 1599-1614”. Historia 23 (1988): 295-325. 